\title{
The turning points of revenue management: a brief history of future evolution
}

\author{
Ian Seymour Yeoman and Una McMahon-Beattie
}

\author{
lan Seymour Yeoman is a \\ Futurist at the School of \\ Management, Victoria \\ University of Wellington, \\ Wellington, New Zealand and \\ European Tourism Futures \\ Institute, Stenden University \\ of Applied Sciences, \\ Leeuwarden, The Netherlands. \\ Una McMahon-Beattie is the \\ Head of Department at the \\ Department of Hospitality and \\ Tourism Management, Ulster \\ University, Belfast, UK.
}

\begin{abstract}
Purpose - The primary aim of revenue management (RM) is to sell the right product to the right customer at the right time for the right price. Ever since the deregulation of US airline industry, and the emergence of the internet as a distribution channel, RM has come of age. The purpose of this paper is to map out ten turning points in the evolution of Revenue Management taking an historical perspective.

Design/methodology/approach - The paper is a chronological account based upon published research and literature fundamentally drawn from the Journal of Revenue and Pricing Management.

Findings - The significance and success to RM is attributed to the following turning points: Littlewood's rule, Expected Marginal Seat Revenue, deregulation of the US air industry, single leg to origin and destination RM, the use of family fares, technological advancement, low-cost carriers, dynamic pricing, consumer and price transparency and pricing capabilities in organizations.

Originality/value - The originality of the paper lies in identifying the core trends or turning points that have shaped the development of RM thus assisting futurists or forecasters to shape the future.

Keywords History, Pricing, Futures, Revenue management, Technological development

Paper type Research paper
\end{abstract}

\section{Introduction}

The primary aim of Revenue Management (RM) is selling the right product to the right customer at the right time for the right price. Ever since the deregulation of airline industry in the USA, and the emergence of the internet as a distribution channel, RM has come of age and is a topic of importance in tourism, hospitality and services management. Taking an historical perspective, this paper maps out ten turning points in the evolution of RM. Thus, this paper illustrates how history shapes the future based on Alonso's (2010) and Hobsbawm's (1995) premise that "the return to history" provides a critical praxis of the horizon of expectations and illustrations. Futurists, therefore, look to the past as a representation of the future. Indeed, Luhmann (1976) noted that the history of the future does not reach back very far in the terms of human activity compared to the creation of the Planet Earth. Technological advancement within this context has an even shorter history and RM is a phenomena of the twenty-first century (Yeoman, 2016).

\section{Turning point 1: Littlewood's rule}

The earliest description of forecasting models can be found in passenger bookings and cancellation models (Beckmann and Bobkoski, 1958; Weatherford, 2016; Yeoman and McMahon-Beattie, 2011). As the focus was on cancellations, no shows and misconnections, it was not until the development of the Littlewood's rule in 1972 that data were used to forecast load factors based upon advanced bookings from 1 to 13 weeks (Littlewood, 2005). The opportunity to develop an algorithm to address revenue maximization was linked to 
technological developments with the introduction of a sophisticated computer reservations system at the British Overseas Airways Corporation. Littlewood's algorithm enabled a forecasting system to be built based upon a seat inventory problem for a single leg with two fare classes. The significance was that Littlewood was the first to propose aggregating flights from low-demand original and destination in broader categories, i.e., Europe to Nairobi, thereby establishing the first static single resource-based RM model (Weatherford, 2016).

\section{Turning point 2: Expected Marginal Seat Revenue (EMSR)}

In 1987, Belobaba presented the concept of EMSR which extended Littlewood's rule and became the foundation of most airline RM systems (RMS). EMSR was very significant and is still today the foundation of many RMS (Belobaba, 1987; Yeoman, 2016). It employs heuristic decision rules for nested booking through adding protection limits that are calculated by applying Littlewood's rule to successive classes. EMSR was further refined to become EMSRb, improving optimal solutions by 0.5 per cent (Belobaba, 2016). EMSRb is based on an approximation that compares two classes but it does take the statistical averaging effect into account. Instead of aggregating protection levels, as EMSRa does, it aggregates demand.

\section{Turning point 3: deregulation of the US air industry}

According to Vinod (2016), yield management came into existence on a significant scale after the deregulation of the US airline industry. Button (2015) notes that the US Domestic Airline Deregulation Act (1978) was a dramatic event in the US economic policy, dismantling the comprehensive system of government controls. For example, before deregulation, airlines operated in tightly regulated environments in which Civil Aeronautics Board (CAB) approved routes and set fares guaranteed airlines a 12 per cent return on flights that were 55 per cent full. After deregulation, there was an explosion of fares offered by competing airlines. Indeed, between 1976 and 1990, average fares for US domestic passengers fell by 30 per cent in real terms. One of the new carriers entering this deregulated market was PEOPLExpress and it threatened the existence of American Airlines with deeply discounted tickets. As a response, America developed the world's first yield management system, DINAMO (Dynamic Inventory Allocation Modeling Optimizer). In 1985, American Airlines introduced non-refundable Ultimate Super Saver fares which were priced lower than PEOPLExpress's fares. For the first time, YM analysts at American Airlines were able to explicitly control the availability of the deeply discounted fares. PEOPLExpress responded with further discounts, which were unsustainable thus forcing them out of business.

\section{Turning point 4: single leg to origin and destination (O\&D) RM}

Poelt (2016) notes for point-to-point carriers with few connections, leg control is sufficient but for a network carrier with a hub-and-spoke systems and an O\&D fare structure leg control is suboptimal. The fare structure of a network carrier usually differentiates by market (point of sale) and is non-addictive in the sense that a ticket for the connecting itinerary A-B-C is cheaper than the sum of the tickets for $\mathrm{A}-\mathrm{B}$ and $\mathrm{B}-\mathrm{C}$ in that booking class. The problem of leg control is that it cannot distinguish between local and connecting traffic in availability control. O\&D control, also called network RM, has the ability to distinguish between local and connecting passengers and huge overlapping fare ranges of booking classes. Two types of O\&D control have been established in the past, namely bid pricing and displacement-adjusted virtual nesting (Talluri and Ryzin, 2004). A bid pricing approach starts with all availability and booking requests routed through the airline's inventory systems. This is called the seamless link (distribution capability). The inventory evaluates an incoming booking request by corresponding O\&D fares. Availability is given in a booking class if the fare of the class is greater than the sum of the bid process of the concerned legs. The bid prices and the O\&D fares are provided by the airline's RM and pricing tools. Fundamentally, O\&D forecasting allows for the capture of basic demand characteristics like seasonality and customer behaviour. 


\section{Turning point 5 : the use of family fares}

In early 2000s, fare families has become a popular way to organize and market airline products. Typically, fare families corresponds to product categories that differ by features such as refundability or baggage fees while products within a family may be differentiated to a lesser degree (Walczak and Kambour, 2014). The airline product redesign has been prompted by the shift in customer behaviour and emergence of unrestricted or lightly restricted fares offered by new market entrants and the low-cost carriers (LCCS). Interestingly, the focus on airline products organized along a handful of product attributes has also been reflected on the travel search side, with at least one vendor offering to travel agents airline fare searches organized in fare families so that customers can compare side-by-side features such as flexibility, refundability (e.g. non-refundable, refundable with penalty and fully flexible) and types of ancillary products, in addition to price. The fare families has thus become an important approach to selling airline seats and there are a number of airlines that actively sell their products in this way (Walczak and Kambour, 2014).

\section{Turning point 6: technological advancement}

Technological advancement has meant that computer processing power enables the running of complex algorithms to simulate airline network optimization problems. Moore's Law is typically used to describe the rate of long-term advancement in computing as a driving force behind technological changes (Yeoman, 2012). In 1975, a prediction was made by Intel co-founder Gordon E. Moore that the number of components in integrated circuits would double every year, increasing yields and driving costs per transistors down. The prediction was amazingly accurate. Brunger (2016, p. 243) recognizes that the development of RM is attributed to technological advancement:

Looking back from the vantage point of 2015 with its rich, vibrant RM community and healthy RM dialog, it is hard to imagine how isolated early practitioners of RM were. There existed many fewer experts, very little background literature, almost no primary research and, significantly, no Journal of Revenue and Pricing Management. The computer tools were primitive. There were no PCs or even portable laptops, and no dedicated RM IT resources within most airline organizations. Computer languages and particularly input/output protocols were not supportive to the early efforts - there was a predominance of very sequential coding languages, loops within loops. Those who set out to write early systems even for major carriers lived in isolation, trying to invent theory on the fly and/or to replicate the best of the simplistic manual heuristics by which RM analysts were trying to come to grips with an increasingly complex environment.

\section{Turning point 7: the emergence of the LCC}

The LCC offer lower fares and fewer frills than the traditional carriers, operating both hybrid hub-and-spoke and point-to-point networks. The largest LCCs in the US domestic market, Southwest, JetBlue and AirTran, have gained significant traffic shares not only by offering lower fares but also by expanding their networks to serve more destinations (Ben Abda et al., 2011). The key competitive advantage of the LCCs is their ability to offer significantly lower fares, or at least to create the image of offering lower fares, while being able to generate profits by having low unit costs. The impact of the LCC on fares is well documented. Southwest Airlines entrance onto a route typically resulted in 48 per cent decrease in average fare and a 200 per cent increase in passenger traffic and low fares were directly responsible for $\$ 3.4$ billion in savings for passengers in 1998. According to Belobaba (2011), LCCs have changed the global airline industry, for better and worse. For consumers, LCCs expanded travel options to include basic air transportation at previously unheard-of low fares. For legacy airlines, the new competition from LCCs not only forced them to respond with comparable pricing to protect market share, it also led to unprecedented cost cutting. Arguably, LCCs provided the impetus for the most dramatic restructuring of the airline business since the start of deregulation in the USA in 1978, leading to tremendous improvements in employee and aircraft productivity for successful airlines, bankruptcies and/or liquidation for others. From a RM's perspective, Belobaba (2011, p. 20) accounts for the changes as:

The legacy airline pricing model that allowed traditional RM systems to function so well started to unravel around 2000. Rapid growth of LCCs increased the number of price and itinerary options 
available to consumers, and LCC marketing strategies emphasized their less restricted or "simplified" fare structures. New internet distribution channels gave more consumers more information than ever before about alternative fare options. Passengers became much less willing to pay 5,8 or even 10 times the lowest available fare for travel on the same flight in the same economy class seat. At the same time, severe cost cutting by legacy carriers led to service quality cutbacks that all but eliminated consumers' perceptions that legacy carriers offer a better product. LCCs led a pricing revolution toward "simplified" fare structures that most airlines followed. Fare simplification involved the removal of segmentation restrictions on lower fares, most typically round-trip purchase and minimum stay requirements. Legacy carriers were effectively forced to match the LCC fare levels and to simplify their own fare structures in order to remain competitive. Although welcomed by consumers, simplified fares took from the airlines their most effective way of segmenting business and leisure demand.

In response, RM researchers needed to develop new methods for demand forecasting, inventory optimization and estimation of passenger willingness-to-pay (WTP). As Belobaba (2011, p. 21) further states:

Examples of new forecasting approaches that incorporate the concepts of WTP and sell-up. For fully undifferentiated fares, Q-forecasting forecasts the maximum potential demand for the lowest fare, then uses estimates of WTP to forecast demand for higher fare classes conditional upon closure of each lower class. Hybrid forecasting generates separate demand forecasts for price- and product-oriented demand, and is appropriate for fare structures with at least some segmentation restrictions. Traditional RM forecasters can be used to estimate product-oriented demand, whereas Q-forecasting can be applied to forecast price-oriented demand [...]. Generating forecasts of demand by WTP, however, is not enough to ensure that revenues will be maximized, particularly on flights with more capacity than demand. RM optimizers also needed to be modified to incorporate information about the propensity of passengers to buy down in a given fare structure. The concepts of "fare adjustment" and marginal revenue optimization allow airlines to apply separate controls to restricted and unrestricted fare structures on the same flight leg. This methodology reduces the fare value fed to the seat allocation optimizer for less restricted fare structures with greater risk of revenue loss due to buy-down, closing lower fare classes earlier in an attempt to encourage sell-up. This fare adjustment theory has been extended to a variety of RM systems and can be applied to almost any fare structure.

\section{Turning point 8: dynamic pricing (DP)}

Existing RMS base their recommendations on historic observations and do not explicitly consider competition. This means that RMS recommendations often are not appropriate for real-time competitive situations (Fiig et al., 2015, 2016). In order to address this issue, we saw the development of DP which is an extension of RMS that dynamically calculates the optimal price, taking into account the airline's strategy, customer-specific information and real-time alternative offerings. By optimizing the contribution within the shopping session, DP has a more current and detailed view of demand and can improve RMS performance. DP also referred as surge pricing, demand pricing or time-based pricing allows prices to respond to current market conditions. Emerging from the airline and hotel industries, DP has been applied in retailing with online retails to adjust the price of products according to competitors, time, traffic, conversion rates and sales goals. The aim of dynamic pricing is to increase revenue and profit (Deksnyte et al., 2014; Yeoman et al., 2016). Whereas in sport, professional teams have used dynamic pricing structures to boost revenue taking into factors such as date of purchase, game opponent, weather and view (Drayer et al., 2012).

\section{Turning point 9: the consumer and price transparency}

Yeoman (2016) argues that the ability of consumers to compare prices and achieve the best deal as a consequence of the emergence of online travel agents as a major transformation. Indeed McMahon-Beattie et al. (2016) review the evolution of RM as more than operational research and mathematical algorithms and support a holistic approach encompassing the consumer behaviour. If the primary aim of RM is selling the right product/service to the right customer, at the right time, for the right price, in order to generate revenue from perishable capacity, then an understanding of consumers and their behaviour is critical to its effective development and implementation. This has become even more important in recent years as a result of the global economic strains of recession and exchange rate changes that have seen the rise of the 
"strategic customer" empowered by smartphone technology and the emergence of price comparison/aggregator websites. Customers continue to seek an absolute value and the best price available. Simply put, the dynamics of supplier pricing are more visible to consumers and, in response, they are adapting their buying behaviour.

\section{Turning point 10: pricing capabilities in organizations}

Liozu (2016) has indicated that price is becoming increasingly important within firms at both tactical and strategic levels in order to increase competitive advantage and firm performance. For the past 20 years, faced with increased business and pricing complexity, pricing scholars and practitioners have paid more and more attention to pricing capabilities, thus linking RM with pricing and taking an organizational perspective (Yeoman and Watson, 1997). Grounded in resource-based view and capability-based view of the firm, pricing capabilities have moved over time from a non-existing concept to an emerging theory.

\section{Concluding thoughts}

$\mathrm{RM}$ has had a huge impact on a range of industries and is now a core function. When American Airlines responded to PEOPLExpres's challenge with a RMS, it offered only four types of fares: first class, regular coach and two discounts which had a 7-day and 21-day advance purchase restrictions respectively. The revolution caused by Littleswood's rule (Littlewood, 2005) and EMSR (Belobaba, 1987) linked forecasting, optimization and reservations management into a single entity. According to Levin and McGill (2009), Littlewood's rule for deciding when to stop selling discounted seats is a simple variant of the well-known newsvendor formula for single period inventory control. Although preceded by years of work on transportation overbooking, the publication of Littlewood's rule can be considered the real beginning of approaches to the management of inventories of perishable services and goods that have evolved into modern RM. From its origins in passenger transportation, RM techniques have spread into diverse areas of both service and manufacturing businesses, and the growth appears to be continuing. Littlewood's pioneering work cannot be underestimated, nor can Belobaba's (1987) EMSR algorithm, which employed heuristic decision rules for nested booking through adding protection limits that are calculated by applying Littlewood's rule to successive classes.

Technological advancement has enabled a new generation of algorithms to address the issues of hub-and-spoke networks for intercontinental carriers. The consumer can now use price comparison software to see a range of fare classes and prices in order to get the best deal. The arrival of the LCC has seen the end of restrictive fares such as Saturday night lay overs with the emergence of new family fares. And now, RM is accepted as a holistic approach to airline business with organizational pricing capability as a driving force for the future.

Looking forward, many problems of RM remain unsolved but the topic is an active area of research from a multidisciplinary perspective, whether operations research or marketing. More industries are applying the techniques of RM such as advertising, cargo and manufacturing. Within the hotel industry, nearly every hotel now has a revenue manager. Looking to the future, there remain challenges given the new forms of distribution channels, changing management practices and consumer behaviour. The contribution of this trend paper sets out the history of RM by identifying the turning points of change. For futurists or forecasters, the challenges are using these turning points as a set of time series points in order to forecast and understand the future.

\section{References}

Alonso, C.J. (2010), "The history of the future”, Romanic Review, Vol. 101 Nos 1-2, pp. 101-4.

Beckmann, M.J. and Bobkoski, F. (1958), "Airline demand: an analysis of some frequency distributions", Naval Research Logistics Quarterly, Vol. 5 No. 1, pp. 43-51, doi: 10.1002/nav.3800050105.

Belobaba, P. (1987), "Air travel demand and airline seat inventory management", PhD, Massachusetts Institute of Technology, Cambridge, available at: http://hdl.handle.net/1721.1/14800 
Belobaba, P. (2011), "Did LCCs save airline revenue management?", Journal of Revenue and Pricing Management, Vol. 10 No. 1, pp. 19-22, doi: 10.1057/rpm.2010.45.

Belobaba, P. (2016), "Optimization models in RM systems: optimality versus revenue gains", Journal of Revenue and Pricing Management, Vol. 15 Nos 3-4, pp. 229-35, doi: 10.1057/rpm.2016.13.

Ben Abda, M., Belobaba, P.P. and Swelbar, W.S. (2011), "Impacts of LCC growth on domestic traffic and fares at largest US airports", Journal of Air Transport Management, Vol. 18 No. 1, pp. 21-5, doi: 10.1016/ j.jairtraman.2011.07.001.

Brunger, B. (2016), "Inventing RM: how it felt to write a revenue management (RM) system without precedents the scene", Journal of Revenue and Pricing Management, Vol. 15 Nos 3-4, pp. 242-6, doi: 10.1057/ rpm.2016.19.

Button, K. (2015), "A book, the application and the outcomes: how right was Alfred Kahn in The Economics of Regulation about the effects of the deregulation of the US domestic airline market?(Airline Deregulation Act of 1978)", History of Political Economy, Vol. 47 No. 1, pp. 1-39.

Deksnyte, I., Lydeka, Z. and Pukeliene, V. (2014), "Dynamic price as bargaining result for revenue maximization in retail”, Ekonomika, Vol. 93 No. 3, pp. 67-83.

Drayer, J., Shapiro, S. and Lee, S. (2012), "Dynamic ticket pricing in sport: an agenda for research and practice", Sport Marketing Quarterly, Vol. 21 No. 3, pp. 184-94.

Fiig, T., Cholak, U., Gauchet, M. and Cany, B. (2015), "What is the role of distribution in revenue management? - past and future", Journal of Revenue and Pricing Management, Vol. 14 No. 2, pp. 127-33, doi: 10.1057/rpm.2015.1.

Fiig, T., Goyons, O., Adelving, R. and Smith, B. (2016), “Dynamic pricing - the next revolution in RM?”, Journal of Revenue and Pricing Management, Vol. 15 No. 5, pp. 360-79, doi: 10.1057/rpm.2016.28.

Hobsbawm, E.J. (1995), Age of Extremes : The Short Twentieth Century, 1914-1991, Abacus, London.

Levin, Y. and McGill, J. (2009), "Introduction to the special issue on revenue management and dynamic pricing", European Journal of Operational Research, Vol. 197 No. 3, pp. 845-7, available at: http://dx.doi.org/ 10.1016/j.ejor.2008.12.001

Liozu, S. (2016), "The evolution and future of pricing capabilities", Journal of Revenue and Pricing Management, Vol. 15 Nos 3-4, pp. 306-16, doi: 10.1057/rpm.2016.20.

Littlewood, K. (2005), "Forecasting and control of passenger bookings", Journal of Revenue and Pricing Management, Vol. 4 No. 2, pp. 111-23.

Luhmann, N. (1976), "The future cannot begin: temporal structures in modern society", Social Research, Vol. 43 No. 1, pp. 130-52.

McMahon-Beattie, U., McCentee, M., McKenna, R., Yeoman, I. and Hollywood, L. (2016), "Revenue management, pricing and the consumer", Journal of Revenue and Pricing Management, Vol. 15 Nos 3-4, pp. 299-305, doi: 10.1057/rpm.2016.17.

Poelt, S. (2016), "History of revenue management - from leg to O\&D", Journal of Revenue and Pricing Management, Vol. 15 Nos 3-5, pp. 236-41, doi: 10.1057/rpm.2016.6.

Talluri, K. and Ryzin, G. (2004), The Theory and Practice of Revenue Management, Springer-Verlag US, Boston, MA.

Vinod, B. (2016), "Evolution of yield management in travel", Journal of Revenue and Pricing Management, Vol. 15 Nos 3-4, pp. 203-11, doi: 10.1057/rpm.2016.15.

Walczak, D. and Kambour, E. (2014), "Revenue management for fare families with price-sensitive demand", Journal of Revenue and Pricing Management, Vol. 13 No. 4, pp. 273-90, doi: 10.1057/rpm.2014.3.

Weatherford, L. (2016), "The history of forecasting models in revenue management", Journal of Revenue and Pricing Management, Vol. 15 No. 4, pp. 222-8, doi: 10.1057/rpm.2016.18.

Yeoman, I. (2012), 2050 - Tomorrow Tourism, Channel View Publications, Buffalo, NY.

Yeoman, I. (2016), "The history of revenue and pricing management - 15 years and more", Journal of Revenue and Pricing Management, Vol. 15 Nos 3-4, p. 185, doi: 10.1057/rpm.2016.36.

Yeoman, I. and McMahon-Beattie, U. (Eds) (2011), Revenue Management a Practical Pricing Perspective, Palgrave Macmillan, Houndsmill, Basingstoke, Hampshire and New York, NY. 
Yeoman, I. and Watson, S. (1997), "Yield management: a human activity system", International Journal of Contemporary Hospitality Management, Vol. 9 No. 2, pp. 80-3, doi: 10.1108/09596119710164821.

Yeoman, I., Wheatley, C. and McMahon-Beattie, U. (2016), "Trends in retail pricing: a consumer perspective", Journal of Revenue and Pricing Management, doi: 10.1057/rpm.2016.35.

\section{About the authors}

lan Seymour Yeoman is an Associate Professor at the Victoria University of Wellington, New Zealand, specializing in the future of travel and tourism. lan learned his trade as the Scenario Planner for VisitScotland where he established the process of futures thinking within the organization using a variety of techniques including economic modelling, trends analysis and scenario construction. He has undertaken similar work across the globe including most recently in Norway, the Netherlands and New Zealand. lan has a PhD in Operations Research from Napier University, Edinburgh and BSc (Hons) in Catering Systems from Sheffield City Polytechnic. lan is the Editor of the Journal of Revenue and Pricing Management and co-editor of the Journal of Tourism Futures. He has published extensively in leading journals and is author and co-editor of 18 books including the The Future of Food Tourism, 2050: Tomorrows Tourism and The Future of Events and Festivals. Ian holds honorary positions at Sheffield Hallam University, Ulster University and the European Tourism Futures Institute. lan Seymour Yeoman is the corresponding author and can be contacted at: ian.yeoman@vuw.ac.nz

Una McMahon-Beattie is the Head of Department for Hospitality and Tourism Management in the Ulster University Business School, Ulster University (UK). Her research includes tourism futures, revenue management and tourism and event marketing. Una has a PhD in Revenue Management and Marketing from the University of Gloucestershire. She is Deputy Editor of the Journal of Revenue and Pricing Management and author of a number of books, chapters and journal articles in these areas.

For instructions on how to order reprints of this article, please visit our website:

www.emeraldgrouppublishing.com/licensing/reprints.htm

Or contact us for further details: permissions@emeraldinsight.com 